\title{
Editorial
}

\section{Do BIOTASP à Internet 2}

Oito de abril de 1996, Auditório da FAPESP. Um grupo de cerca de 40 pesquisadores discute sobre a possibilidade de organizarem um Projeto Especial de Pesquisa em Conservação e Uso Sustentável da Biodiversidade. Fala-se em criar mecanismos para a implementação, no âmbito do Estado de São Paulo, da Convenção sobre a Diversidade Biológica, aprovada no decorrer da Conferência das Nações Unidas sobre Meio Ambiente e Desenvolvimento/CNUMAD (ECO-92) em junho de 1992 e ratificada pelo Congresso Nacional em fevereiro de 1994.

As discussões abordam questões como a complexidade e a abrangência da temática conservação e uso sustentável da biodiversidade, a elevada fragmentação das informações disponíveis sobre a biota do Estado, a inexistência de mapas de campo atualizados e atualizáveis, e a indiscutível premência de uma política que contivesse e revertesse o desaparecimento de habitats e espécies. Outro aspecto muito discutido é o distanciamento entre os pesquisadores que detêm, e continuam a gerar, as informações científicas e técnicas de alta qualidade sobre a biodiversidade e os órgãos que propõem e/ou administram as políticas de conservação e uso sustentável dos recursos naturais do Estado.

O que fazer? Como alterar esta situação? Como contribuir para melhorar este cenário sem perder nossa principal característica, produzir ciência de alto padrão. Todos estavam dispostos a cooperar, a trabalhar em prol de um projeto ainda vago e sem um formato definido, de voluntariamente investir parte de seu tempo e capacidade no desenvolvimento da idéia alí lançada, envolver a FAPESP num grande Projeto de Pesquisas em Conservação e Uso Sustentável da Biodiversidade. Nascia o BIOTASP!

Ao longo dos três anos subsequentes o Grupo de Coordenação do BIOTASP publicou a série Biodiversidade do Estado de São Paulo: síntese do conhecimento ao final do século $X X$, sintetizando o conhecimento até então disponível sobre a biota paulista e a infraestrutura para sua conservação in situ e ex situ. Além disso, promoveu o histórico Workshop de Serra Negra e organizou a comunidade científica em torno de um conjunto de Projetos Temáticos articulados em torno de objetivos comuns. Em março de 1999 nascia o Programa BIOTA/FAPESP - O Instituto Virtual da Biodiversidade.

O Programa BIOTA/FAPESP, que nasceu de uma iniciativa da comunidade científica, representa, sem dúvida, um divisor de águas entre a imprescindível etapa dos inventários sobre a composição do biota paulista e um programa de pesquisas em conservação e uso sustentável da biodiversidade.

Em um programa com este objetivo era necessário não só dar continuidade à importante tarefa de descrever e catalogar espécies, como também desenvolver projetos de pesquisa que incorporassem os aspectos estruturais e funcionais da biodiversidade, a distribuição espacial e temporal dos organismos e as relações entre seus componentes nos diversos níveis organizacionais. Além disso, era também necessária a valorização da biodiversidade, a tentativa de estabelecer um vínculo entre os serviços e produtos da diversidade biológica e os sistemas produtivos.

A partir da criação do Programa ocorreu, concomitantemente, o início dos Projetos Temáticos aprovados e o desenvolvimento das ferramentas de integração, dos dados 
coletados pelos projetos que integram o Instituto Virtual da Biodiversidade. Estas ferramentas, o banco de dados textuais e a base cartográfica digital na escala 1:50.000 foram recentemente integradas pelo SinBiota, o Sistema de Informação Ambiental do Programa BIOTA/FAPESP.

Cinco anos depois, uma análise retrospectiva, evidencia o sucesso de uma experiência ímpar, a criação e implantação do Programa BIOTA/FAPESP. A funcionalidade das ferramentas de integração desenvolvidas pelo Programa nos faz crer que, num futuro não muito distante, elas serão replicadas em outros estados e regiões do país. Idealmente, em alguns anos, teremos diversos Biotas que, interconectados, resultarão em um BIOTA/Br. O processo de criação do BIOTA/FAPESP, entretanto, dificilmente se repetirá, pois ele é o resultado do amadurecimento da comunidade científica do Estado de São Paulo em torno das premissas da Convenção sobre a Diversidade Biológica.

A tônica do Programa BIOTA/FAPESP é a busca incessante de novas ferramentas de integração. O lançamento da BIOTA NEOTROPICA, revista eletrônica "on line only", com o objetivo de publicar e disponibilizar informações relevantes para o conhecimento da biodiversidade da região Neotropical, é apenas mais uma etapa deste complexo processo iniciado em abril de 1996. 